\title{
Mujer afro: voz de reexistencia y esperanza universal*
}

\author{
African Women: Voice of re-existence \\ and universal hope
Mulher Afro: Voz de re-existência $\epsilon$ esperança universal

Justina Caicedo Salcedo

Universidad de San Buenaventura, Cali, Colombia**

RECIBIDO: 3 DE ABRIL DE 2013 - APROBADO: 18 DE MAYO DE 2013

Resumen. Se trata de un trabajo de tipo hermenéutico interpretativo, un profundo y emotivo periplo de caminos y rutas que se entrecruzan donde la Voz es actuante como armonizador común: la voz de La Esperanza, la voz del encuentro y la voz de la permanencia, intenta dar cuenta, de cómo la Mujer Afro ha asumido los retos que el nuevo entorno implica para ella y su relación con otras mujeres Afro en su misma situación, cómo ha respondido al reto de nuevas formas de familia y de crianza de los hijos, y de cómo potencializa su esperanza para integrarse sin perder su identidad y sentido, siendo ejemplo de nuevas búsquedas y alternativas para asumir el papel protagónico que se merece y que le ha sido hasta ahora negado. Son vivencias que nos asoman a saberes, oralidad y simbolismos de la Mujer Afro que sienten es tiempo de que sus voces sean escuchadas.

* $\quad$ Artículo de investigación producto de la investigación realizada por la autora para optar al título de Magister en Educación: Desarrollo Humano, Universidad de San Buenaventura, Cali, dentro del grupo de investigación en Educación y cultura.

** Magister en Educación: Desarrollo Humano de la Universidad San Buenaventura, Cali; Licenciada en Educación Preescolar de la misma Universidad; actualmente continúa sus investigaciones sobre la Mujer Afro y ejerce tanto la docencia para primera infancia como en la universitaria. E-mail: justine512@hotmail.com 
Palabras clave. Mujer afro, mujer afrocolombiana, ancestralidad, saberes, oralidad, hermenéutica simbólica, narrativa, comunidad (Tesauro Unesco).

Abstract. It is a work of hermeneutic interpretive type, a deep and moving journey of roads and routes that intersect where the Voice is active like common harmonizer: The Hope's voice, the voice of the encounter and the voice of the permanency, try to express and contain, how the African-American Woman has assumed the challenges that the new environment implies for her and its relationship with other African-American women in its same situation, how she has responded to the challenge in new family ways and of the children's upbringing, and of how potential up its Hope to be integrated without losing its identity and sense, being example of new searches and alternatives to assume the protagonist paper that deserves and that it has denied until now. They are experiences that appear us to knowledge, language and symbolisms of the African-American Woman that feel it is time that their voices are listened.

Keywords. African-American women, African-Colombian woman, heritance, knowledge, oral heritage, symbolic hermeneutic, narrative, community (Thesaurus Unesco).

Resumo. Trata-se de um trabalho de tipo hermenêutico interpretativo, uma profunda e emotiva viagem por caminhos e rotas que se entrecruzam onde a Voz é atuante como harmonizador comum: a voz da Esperança, a voz do encontro e a voz da permanência, tenta dar conta de que maneira a Mulher Afro assumiu os retos que o novo ambiente implica para ela e sua relação com outras mulheres Afros na mesma situação que ela, como respondeu ao reto de novas formas de família e da criação dos filhos, e de como potencializa sua esperança para integrar-se sem perder sua identidade e sentido, sendo exemplo de novas buscas e alternativas para assumir o papel protagonista que merece e que lhe foi negado até agora. São vivências que nos mostram saberes, oralidade e simbolismos da Mulher Afro que sentem que já é tempo de que suas vozes sejam escutadas.

Palavras chave. Mulher afro, mulher afro colombiana, ancestralidade, saberes, oralidade, hermenêutica simbólica, narrativa, comunidade (Tesaurus Unesco). 


\section{Introducción}

Intento contarles con mi voz y con otras voces de mujeres afro de distintas latitudes y condición, los caminos y las rutas que hemos creado para escuchar-escucharnos y que nos escuchen en el día a día con un horizonte esperanzador para nosotras, para nuestros hijos e hijas y parientes.

Algunos elementos de soporte pertenecen a un maravilloso trabajo realizado por la profesora afro norteamericana Farah Jasmine Griffin en «When Malindy Sings: A Meditation on Black Woman's Vocality» (Griffin, 2004).

En todos los casos, se trata de voces profundas y humanas, dueñas de un registro diverso y a veces muy particular; voces que desde toda condición nos han sostenido e impulsado a la vida y que en mi caso guardan una poderosa carga de esperanza para tod@s los que las escuchamos. Porque sabemos que como mujeres Afro podemos y debemos enunciarnos, precisamente a partir de nuestra diferencia.

\section{Voz de mujer afro}

«Al principio no había palabras. Al principio estaba el sonido y todos sabían que lo sólidamente real era lo que sonaba.» (Toni Morrison) ${ }^{1}$, citada en (Griffin, 2004, p. 112).

No había luz en el principio, sino un universo de sonidos, una voz de mujer, y dependiendo del contador del cuento, la voz de una mujer Negra. Comenta la profesora Griffin y refiere al Musical Voodoo, cantado por Cassandra Wilson con la vocalista africana Angélique Kidjo CD titulado «Traveling Miles.» (Griffin, 2004, p. 118).

Estos epígrafes describen el impacto de la emisión-omisión de los sonidos de la voz de la mujer afro, contando su realidad y su horizonte, alrededor de su vida, en su entorno local y global.

En Colombia, desde las profundidades de las raíces afro descendientes, la Voz de la Mujer Afro ha jugado un papel importante en la configuración de la identidad nacional, como madre nutriente de sus hijos y de los

1 Toni Morrison no es la primera escritora negra de Norteamérica, pero sin duda es la fundadora de una literatura escrita desde y para los negros que, como ella misma, se identifican como afroamericanos. Su narrativa es asimismo genuina y genéticamente femenina. Fue galardona con el Premio Nobel de Literatura 1993 (Traducción de la autora).

ITINERARIO EDUCATIVO • ISSN OICI-2753 • AÑO XXVII, N. ${ }^{\circ}$ GI • ENERO - JUNIO DE 2OI3 • P. I3I-I49 
hijos del colonizador, como voz de unión por ser la que aporta y acude a pesar de ser la que menos intereses posee, la menos tenida en cuenta.

Como mujer afro caleña cuyas raíces germinaron en Santander de Quilichao al lado de dos abuelas, una madre, cuatro tías que traspasaron las barreras de la discriminación y exclusión por el color de la piel en espacios académicos, profesionales, laborales, sociales y económicos, estoy familiarizada con estas voces, que han alimentado mi espíritu, alma y cuerpo forjando una mujer Afro sensible a las voces propias y ajenas que la rodean.

Diversas rutas desde distantes lugares me han llevado al encuentro con un grupo de mujeres afro colombianas transformadas en su adentro, para actuar de manera impactante en su entorno. Es la necesidad de ir más allá del discurso estatal que dice incluirnos, pero que no escucha, discurso en el que no encontramos nuestros registros, pues se auto complace en la homogeneidad mientras nos ignora. Los encuentros, las conversaciones, para escuchar-escucharme-escucharnos ha creado y fortalecido nuestra esperanza de Mujeres Afro, llenándonos de Paz, Gozo, Alegría y Amor, que se irradia a hijos, hijas, esposo y a toda la parentela.

\section{Voz de la esperanza}

Griffin (2004) dice también, que de acuerdo con Southern (1971) ${ }^{2}$, profesora emérita de música y estudios afroamericanos de la Universidad de Harvard, la cantora negra en los primeros tiempos de la nación americana, fue descrita y distinguida por su «alta intensidad, uso de efectos especiales de falsete, gritos, graznidos y tonos guturales».

«La literatura Americana contiene numerosas referencias de mujeres esclavas de tiempos coloniales que cautivaron jóvenes audiencias y de adultos con sus cuentos tradicionales». Eileen Southern

Estaba favorecida sigue Eileen Southern, por una voz fuerte y clara, pero los europeos generalmente describieron los sonidos de la voz africana como «un sonido nasal fuerte» o «muy ruidoso y chillón».

2 Experta de la música Afroamericana, Eileen Southern es una acreditada y documentada preservadora de las tradiciones musicales afro aún las ignoradas por el mundo académico. En un tiempo en que se pensaba que el Jazz y el Blue era toda la música Afroamericana, Southern mostró que desde el 1600s, los negros en América crearon una rica y variadamente diversa música que va desde los spirituals y canciones populares a trabajos corales y sinfónicos. 
Desde ese lugar relegado por cuestiones de raza y de género la mujer Afro en la nación colombiana, fue relegada, sus voces de cantora, siempre estuvieron asociadas, en el mejor de los casos, con ritmos y modas considerados vulgares por su vena de procedencia popular. Allí se ha sostenido, alimentada a veces por la nostalgia y un frecuente deseo de retorno al paisaje de las riberas de sus ríos y a unas prácticas culturales y de comportamiento que se mezclan con el horror de las vivencias que dieron origen a su salida de la región que habitaban a orillas de ríos en letanía innumerable como Telembí, Telpí, Satinga, Timbiquí, Guapi, Nambí, Patía, Ispí. Y que son quienes a partir de sus grupos familiares han dado lugar a asentamientos afro colombianos en corregimientos como el de Villagorgona municipio de Candelaria en el departamento del Valle del Cauca, igual que en todos los valles interandinos de los municipios del Valle del Cauca en especial en los de Florida, Pradera, Cerrito, Candelaria y Zarzal.

Allí en Villagorgona, en situación de «destierro» un grupo de mujeres viven la desesperanza, preguntándose sin lograr respuesta sobre su destino, y la rudeza de la suerte que les ha tocado vivir, se interrogan ¿Cómo conseguir ellas, llenar el estómago de sus hijas e hijos y abuelos? ¿Cuál será el futuro y la educación de sus niñas, niños y jóvenes? Y illegarán al menos a culminar la secundaria? ¿Cómo conquistar oportunidades académicas, laborales, profesionales, sociales para su familia, contribuir positivamente en la comunidad y en el planeta?

Sucesos violentos, y amenazas para ellas y su familia les han traído y un entorno discriminatorio les obliga a responder con una resistencia eminentemente cultural, con pautas diferentes de relación con el entorno y una captación distinta de lo económico.

La condición campesina de estas mujeres se refleja en su conocimiento tradicional de las plantas y sus diversas propiedades que pasan por lo medicinal, aromático, culinario, cosmético y mágico-religioso, que son sembradas generalmente en una especie de palafito ${ }^{3}$ llamado azotea, para evitar que se pierdan cuando hay grandes crecientes, y de otras técnicas para adecuación y cultivo de la tierra, y en su extrañeza de estas prácticas dado que acá no tienen acceso a tierra alguna, y en el mejor de

3 Vivienda o edificación construida sobre plataformas sustentadas por pilotes o postes hincados en el suelo, situada en aguas interiores poco profundas de lagos y ríos. Microsoft @ Encarta @ 2009. 
los casos son sus esposos quienes se desempeñan en fincas e ingenios en las labores agrícolas y son quienes proveen el sustento familiar.

\section{Voz de la alegría}

\section{Origen de la Voz de la Cantante Negra}

«En todo caso la voz es extraña y no familiar, casi de otro mundo. Es una voz capaz de lanzar hechizos, es una voz invaluable como conexión al mundo del espíritu y su habilidad para invocar la presencia de lo divino.» (Griffin, 2004, p. 63).

Es lo que con toda propiedad diría de las voces cantoras de los ritmos tradicionales del pacífico colombiano; y es lo que nos dice la profesora Griffin, validando a continuación figuras del Jazz como Patti LaBelle ${ }^{4}$ en «Isn't It A Shame».

Como mujeres afro-colombianas pretendemos en nuestros encuentros que hemos denominado "Que sigue ahora» re-vitalizar la esperanza en todo nuestro ser y transformar pensamientos estáticos de un entorno humano que nos descalifica como incapaces de decidir y aportar a nuestros hogares y a la comunidad sin habernos escuchado.

Las rutas seguidas son distintas y diversas como las historias de vida - obras de vida que las han reunido, como las de doña Agripina, doña Helena, doña Dioselina y doña Jennifer; mujeres desterradas de la costa pacífica Colombiana sumergidas en espíritu, alma y cuerpo en la desesperanza, al encontrar-se cara a cara en un lugar discriminativo y excluyente, para luego ir al encuentro con otras mujeres afro, que han recorrido esos caminos de la discriminación y de la exclusión y desde su sensibilidad nos cuentan sus experiencias y aprendizajes.

La sala o el patio, el salón de clase de preescolar, sentadas en el muro del antejardín, la cocina, el local de la compra y venta de las plantas medicinales, el rincón del sabor costeño han sido/son nuestros espacios de encuentro, donde conversa-mos, cocina-mos, canta-mos, recitamos, reímos, lloramos, gritamos de alegría, callamos de tristeza por la desesperanza que nos oprime ante un trato racista, clasista, opresor y

$4 \quad$ Patti LaBelle es una legendaria cantante de Soul y Rithm \& Blues estadounidense. 
excluyente, y al que con un grito profundo nos resistimos desde nuestras entrañas, y que dice fuera la desesperanza y viva y vive la esperanza.

Allí se Invita a escucharme-escuchar-escucharnos las alegrías y tristezas, sueños y esperanzas a través de las conversaciones (Lazzarato, 2006), que emprendemos durante algunas tardes de verano y donde se han creado y se crean las rutas que constituyen obra de vida, que cuentan de destierro, de hijos, de paisajes rodeados por el mar o el cauce de los anchos ríos, de palmeras y bosques, perdidos quizá para siempre, y en su lugar sustituidos por un paisaje excluyente y discriminatorio.

Es común hallar en las estrofas de canciones, en la poesía, en loas y alabanzas de tradición popular, en las conversaciones que narran, lo que está sucediendo a nuestro alrededor, la desesperanza que rodea diferentes aspectos de la vida, y la esperanza que re-vive, en los cantos poéticos, el relato oral y acciones determinantes como mujer Afro para un mejor despertar para nosotras y nuestros parientes.

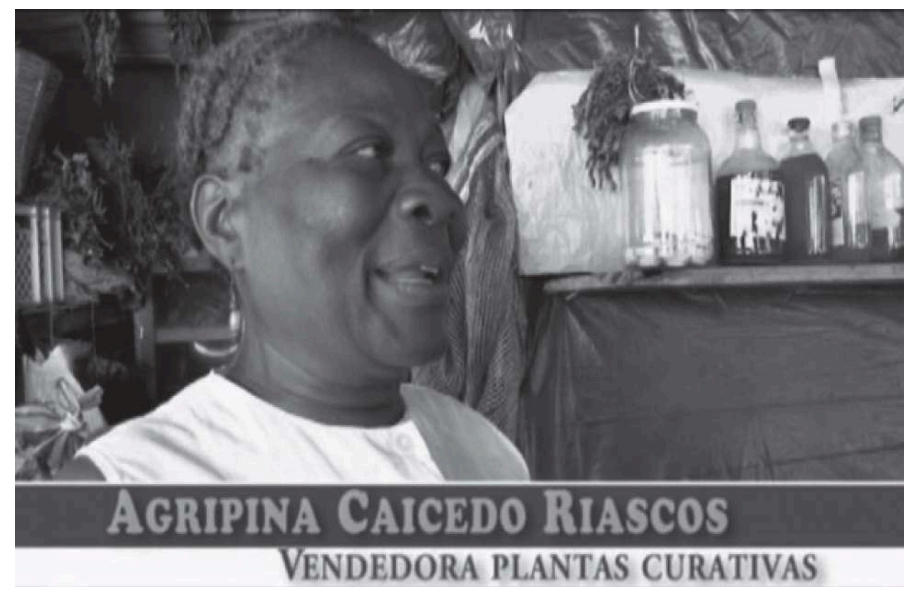

Fotograma del programa televisivo «Somos Pacífico»

Producido por SELLO NEGRO en el curso de la indagación, 2009

La mujer Afro colombiana rural del litoral pacífico poco a poco se va incorporando a una nueva cultura citadina, donde los tiempos de largas conversaciones, cuentos, historietas, son mínimos, en este nuevo lugar donde han llegado, o han sido albergadas, prevalece la comunicación virtual y electrónica entre sus pobladores, permanentemente son miradas con asombro cuando un grupo de mujeres Afro colombianas disfrutan

ITINERARIO EDUCATIVO • ISSN OICI-2753 • AÑO XXVII, N. ${ }^{\circ}$ GI • ENERO - JUNIO DE 2OI3 • P. I3I-I49 
el antejardín de la actual casa ocupada por tres, cuatro y hasta cinco familias, y ellas, mujeres Afro, que a sus ojos y oídos llegan palabras de des-esperanza social, económica, y laboral, re-vitalizan su espíritu y todo su Ser, entonando canciones, poesías, narrando cuentos, leyendas y mitos con su voz, mientras los dedos de sus manos van tejiendo trenzas y tropas ${ }^{5}$, en el cabello ensortijado, la peinadora recrea y reafirma el legado cultural de la mujer Afro, a la vez que se conserva la herencia de esta técnica ancestral, el peinar, la una a la Otra, y Nosotras alrededor, sentadas en el suelo, en el muro, o en sillas, es una tradición colectiva que congrega a las niñas, jóvenes, adultas y adultas mayores, en un espacio integrador, rebosante del relato oral de cada una, el vigor del saber ancestral y el encanto del mismo en su nuevo entorno, va transformando la voz de la mujer, en una voz creadora, forjadora y sustentadora de Esperanza.

\section{Voz de la permanencia}

Además a causa de su habilidad para expresar lo más profundamente humano como el amor, la libertad y lo spiritual, con mucho es representativa de la condición humana... Está enraizada en la tradición y aun así igual que una mariposa, es trascendente, efímera, bella y libre (Griffin, 2004, p. 120).

Por mi condición de Mujer Afro, nacida en Cali — de padres provenientes de una región afro descendiente al Norte del Cauca- y para quien la discriminación y la exclusión es una realidad establecida por las estructuras sociales desde la herencia colonial (Walsh, 2007a, pp. 2-3).

Mis padres me fortalecían y todos los días me decían que tenía que seguir adelante, En casa mis padres, me enseñaron a amarme aceptarme y disfrutar-me como Dios me había creado, independiente de las situaciones discriminativas y excluyentes que habían a mi alrededor, mi madre día

5 Las trenzas y tropas; práctica cultural que a la llegada de los esclavos africanos al continente americano se utilizó como estrategia de resistencia. Estos mapas de fuga, como se denominaron, persisten sincréticamente en la actual diáspora de las poblaciones afro descendientes del pacífico colombiano, ahora como expresión estética. El relato oral de la peinadora conduce inevitablemente a la fuente del conocimiento del legado ancestral y cultural, que subyace en las trenzas y tropas. Desde una perspectiva estética inscrita dentro de las estrategias del arte contemporáneo, las tropas y las trenzas realizadas por las peinadoras afro destacan como una práctica artística susceptible de ser compilada en el registro de sus diseños. 13 Salón Regional De Artistas Colombia. Zona Pacífico, 2009, p. 27. 
a día conversa con mi hermana Irene y conmigo, exhortándonos a ser mujeres valientes, esforzadas, felices y esperanzadoras independiente de las circunstancias que estemos viviendo.

Cada día estoy más y más implicada en los encuentros que hemos titulado "Que Sigue Ahora» donde cada una cuenta que le preocupa o que la hace estar en armonía, entre todas opinamos nos escuchamos y sacamos un aporte vital.

¿Cómo entonces afrontar esta realidad de hechos cumplidos en la vida de mujeres afro colombianas, ante una realidad incomprensible desde su óptica de valores, difícil desde la mirada de su sobrevivencia y la de su familia? Solo queda: re-construir, re-significar nuestros cuerpos en términos fannonianos (Oto, 2006, p. 3) re-pensar, re-conocer nuestros saberes y ancestralidad, para re-existir, re-crear nuestros hijos, hijas y relaciones.

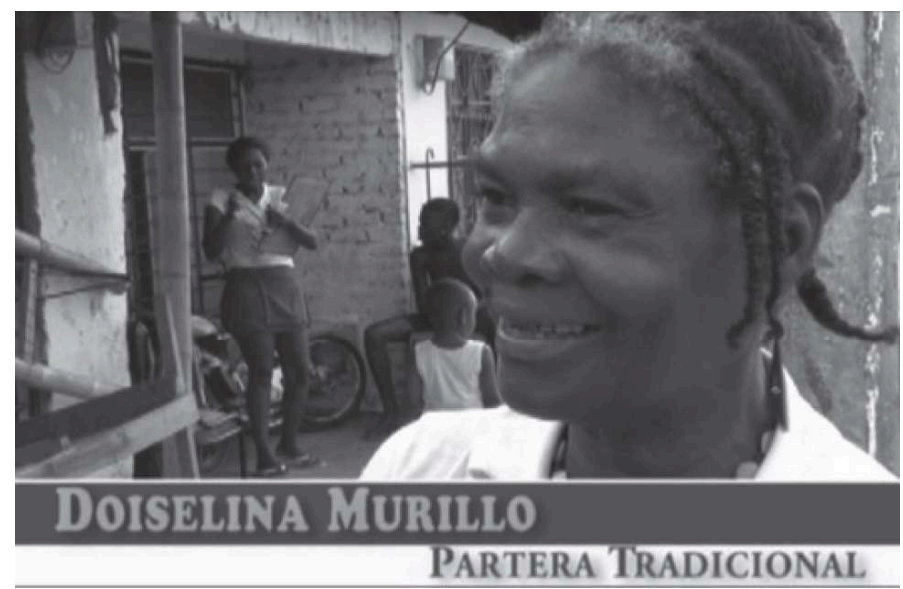

Fotograma del programa televisivo «Somos Pacífico» producido por SELLO NEGRO en el curso de la indagación, 2009

La Mujer Afro es resistente-re-existencia ha llamado la atención y probado su valor positivo a la luz de nuevos desarrollos sociales que develan la necesidad de una cierta distancia de la homogenización impuesta por la modernidad (Walsh, 2007a, pp. 3-8) y la necesaria búsqueda y/o construcción de una alteridad.

La Mujer Afro con su vivencia dentro/desde una tradición ancestral propia y su contacto/vínculo con la institucionalidad dominada en

ITINERARIO EDUCATIVO • ISSN OILI-2753 • AÑO XXVII, N. ${ }^{\circ}$ 6I • ENERO - JUNIO DE 2OI3 • P. IBI-I49 
países como Colombia, por una concepción andino centrada del mundo (Quijano, 2008) de las relaciones y de la identidad; sabe, conoce y sufre la tensión entre la institución y su propio horizonte cultural.

Son luchas que en este momento son parte de la agenda de las mujeres Afro en Colombia enunciadas en publicaciones como la revista publicada por la red de Mujeres Afro KAMBIRI, para que se reconozca, aunque sería preferible que también se comprenda los universos simbólicos que le dan sentido y legitiman su lugar social.

Para la Mujer Afro se trata y ha tratado siempre de la construcción de una familia dentro de un tipo de comunidad que se desarrolla por un cauce que se caracteriza por el tiempo, así como los intereses y estilo de vida compartidos, donde se habla con la propia voz y donde se habla y escucha de lo que se vive, se siente y afecta a una.

\section{Con voz de cantora}

Hoy, me marcho con mi lira a donde pueda encontrar

el amor del cielo azul, la libertad de gritar

Me detendré en cada pueblo, para así poder plantar Un rosal que inspire versos con el color de la paz.

Antología Poética. Perla de Ébano. 2002

Terminaría insistiendo en que la Mujer Afro está y se siente comprometida con la sobrevivencia de todas las personas, hombres y mujeres. No es «separatista», con la excepción de los temas de natalidad y salud de la mujer. Y por supuesto que reclama por un feminismo Afro que dé cuenta de su particular visión, cultura y situación en el mundo.

Su notoriedad como poeta y escritora -dos premios nobel de literatura universal- refleja las necesidades de un mundo en crisis, que comparte con los desplazados en la búsqueda también de este lugar: aquel que le permita, una vez frente al espejo, reconocerse nuevamente y -en el caso colombiano-devolverle a sus comunidades la posibilidad de moverse libremente por los territorios ancestrales, poder andar por los lugares y el espacio donde se realiza, se crea y se recrea su cultura, y donde los afro-colombianos han establecido un conjunto de relaciones entre las comunidades y la naturaleza y entre las comunidades y el conjunto de la sociedad. 
Hay diferencias para la población afro en general y para la mujer afro en particular, entre sus ancestros y su ahora, entre la vida rural en los vericuetos de ríos perdidos en la selva y la vida en las grandes ciudades, acompañada de cierto vacío dejado por el desarraigo, para vivir nuevos acontecimientos en otra cultura más allá de su propia comunidad y de sus parientes, y que solo se puede traducir en el lenguaje de la metáfora. La carga más pesada en esta situación de desplazamiento/destierro sufrido por las comunidades ancestrales afro colombianas, lo sobrelleva la Mujer Afro, la cual cuando se moviliza, lo hace con sus hijos y casi siempre, en condiciones de no-retorno, como lo muestran los testimonios de mujeres Afro (Caicedo Salcedo, 2010).

La transformación vital que ha surgido en este recorrido de mirarmirarme-mirarnos, de escuchar- escucharme- escucharnos ha movilizado todo mi Ser y el de Otras a crear espacios de encuentros afro-femeninos y ser escuchadas en casa, en la vecindad, en lo local y en lo global.

Reconocemos como parte de nuestro trasfondo y actualidad ancestral como Mujer Afro, los cantos, loas, poesía y los cuentos, que afirman el desarraigo y silenciamiento social, cultural y moral; y conduce el discurso por un «entremedias», un discurso que solo adquiere sentido en la subjetividad que nos separa y diferencia.

Bajo la mirada de los estudios culturales ¿ No podría esta distorsión de las palabras ser una resistencia cultural velada y no-tan velada? ¿ No estaría poniéndose de manifiesto, en lugar de una adaptación pasiva a la cultura dominante, la expresión de su propia desazón ante su situación y el injusto trato diferenciado hacia ella y sus hijos?, ¿no sería ello una manifestación de resistencia creativa, que busca en la metáfora y la apelación directa a la Virgen mostrar su propia situación?

La distorsión de la pronunciación o de la palabra misma se constituye en un mecanismo para distanciarse de lo acontecido e imprimirle un sello personal a la narrativa. Que por supuesto, es una aspiración libertaria, más allá de su piel negra, como lo expresara Fanon, sino la búsqueda de un compromiso con el Otro, el que escucha, para que la verdad arroje una claridad esencial sobre la sociedad y sobre el mundo.

El análisis del discurso colonial ha llevarse, por ello, a la búsqueda de momentos de resistencia, no ceñirse únicamente a la contra- 
representación; y la ficcionalización de idearios raciales como contrapunto, y mas bien ha de perseguirse en los leves e insidiosos por casi imperceptibles- desplazamientos de la autoridad y la relación con la Iglesia Católica como principal presencia institucional en las comunidades rurales del Pacífico colombiano, en el énfasis puesto a propósito en las figuras intercesoras como la Virgen María.

Para ilustrar esto, siguiendo con el caso antes citado: «Señores los de la iglesia, /...perdonarán / Voy a meter mi cuchara. /...me avisarán / Que si no la saco llena /...perdonarán» (Arrullando con María». Del Centro Pastoral Afroamericana, p. 50).

Para la Mujer Afro del pacífico colombiano, la cuestión de autoridad más relevante es la de la Iglesia y el los que denoto, intencionalmente la autora y luego la cantora, «corre» esa autoridad, para introducirse ella «mi cuchara», mientras conserva todas las formas de cortesía y de buen trato, con un continuo y bien rimado «perdonarán».

Esto mismo se repite en otras manifestaciones orales y canciones del pacífico colombiano, referidas al mismo efecto de «corrimiento» de la autoridad en otros contextos y con mayor frecuencia a la recurrencia a la condición intercesora de la Virgen María. A ella también se referencian la identidad con ella como «madres de sus hijos/as» para los cuales reclama justicia, pero ante todo reclama, que se le reconozca con su propia voz, su propio conocimiento acerca de lo necesario a sus hijos/ as, sus posibilidades epistémicas y creadoras.

Fanon invitaba a ejercer la resistencia mediante la construcción de una literatura nacional genuina (entendida como expresión identitaria) y capaz, por ello mismo, de contrarrestar el asimilacionismo cultural y de sus representaciones que fomentan el estereotipo, entre otros, de la mujer Afro como carente de educación, mal informada y solo apta para el servicio y placer de un(a) amo(a).

Solo ese continuo acto de re-existencia al re-definirse ha conservado su Esperanza, mientras permanecían ocultos sus cantos, sus alabaos, su poesía inspirada en su terruño y fuera de él, por los acontecimientos que día a día movilizan su vida, la de sus hijos e hijas, y la de sus parientes. 


\section{El desarrollo y la modernidad para la mujer afro}

Para abordar una línea argumentativa que nos aproxime al impacto y realidad del desarrollo entre la Mujer Afro, intento primero que nada, mostrar que se trata de una dinámica de progreso, modernización y desarrollo que evidencia un marcado deterioro en las condiciones de vida de la gente Afro y aún más en la Mujer Afro.

Así mismo, mi abordaje se hace desde una perspectiva hermenéuticasimbólica desde la cual, el ser humano potencializa su imaginario el cual se interpela y se comunica todo el tiempo consigo mismo y con el Otro.

La comprensión hermenéutica de las cosas no es una mera captación racioentitativa de las cosas...tiene que captar no lo que se dice (el mero significado) sino el sentido (lo que quiere decirnos algo/alguien en el contexto humano de la significación axiológica (Ortiz-Oses, 2009, p. 10)

El sometimiento ejecutado desde el estado para con las «singularidades» (Lazzarato, 2006) que emergen desde vertientes no euro-céntricas, que proponen sentidos diversos y agenciamientos culturales diversos, ha mantenido a la Mujer Afro en estado de total invisibilidad.

Es en ese lugar marginal, donde a la Mujer Afro, le ha sido dado, estar en contacto con sus ancestros, su tradición oral y la reinvención de ésta en la interpretación y asimilación de nuevos acontecimientos y situaciones, con sus manifestaciones gestuales y su tradición oral, interpretando el mundo y dándole sentido por el contacto con su propia alma.

El desarrollo de la mano de la modernidad, desafía ese sentido y esa interpretación, el esfuerzo para retener a la propia familia alrededor de valores, usos y tradiciones se hace insostenible ante la violencia y la ciega irracionalidad de un estado guiado por la economía de la explotación, el gran capital y las bandas armadas.

Es la sesgada interpretación del desarrollo y la modernidad, las que causan tanto el desplazamiento forzado como el desplazamiento voluntario, en un caso por acciones de desalojo de hecho instrumentada por intereses del gran capital y en el otro por la seducción de un mejor vivir en las grandes ciudades o poblados de cabecera municipal con su acceso a servicios públicos, educación y trabajo. 
Es un desarrollo que ha ido desenraizando al sujeto de su terruño pacífico, rompiendo el paisanaje, esparciendo a los paisanos, cortando la savia, arrancando-nos del árbol que nos une y da sentido a nuestra existencia en el convivir comunitario complementado con la naturaleza y el sostenimiento económico que emerge desde sus saberes ancestrales.

Es Escobar (2005) quien dice:

Hablamos de espacios profundamente vinculados a la cultura y al lugar, relacionando íntimamente la política de la diferencia y política del lugar, donde la(s) economía(s), la(s) existencia(s), la(s) epísteme(s), los sujetos y el poder, se (re)configuran a partir de sus singularidades (pp. 11, 14).

A la Mujer Afro nunca, hasta recientes eventos, le ha sido reconocido ese espacio más allá de su propia comunidad Afro, donde pueda Ser reconocida como Ser humano portador y dador de afectividad, emociones y sentimientos.

De allí que cuando esta persona Mujer Afro se enfrenta al interrogante de ¿Quién soy yo? ¿Quién eres tú? toda la narrativa de su paisaje, sus tradiciones y usos dan respuestas que no por menos entendibles o efectivas en este medio, sean menos ordenadas y plenas de sentido desde su realidad biológico-psico-social (Bhabha, 1994, p. 53).

Es así que para las comunidades Afrocolombianas y en particular para la Mujer Afro, el desarrollo y la modernidad parecen haberla conducido a que le sea negado su derecho a una vida digna, al menos equiparable a la de otros segmentos poblacionales o grupos reconocibles con la caracterización que sea que tomemos como referencia, se repite, que a ella corresponden los más bajos índices de alfabetismo, educación en todos los niveles, ingreso, expectativa de vida, etc., y en cambio tenga la mayor morbilidad-

Hemos olvidado la pregunta, sobre quienes somos en la sociedad tradicional, con sus normas que rigen la vida diaria generadas a través de relaciones cara a cara, en el día a día, históricamente; por la respuesta corta de las sociedades modernas acerca de lo que rige la vida cotidiana, que determina como significamos, cómo interpretamos, cómo vivimos nuestra vida, y que no están producidas a ese nivel de la relación cara a cara, sino que están producidas por mecanismos expertos e impersonales que parten del conocimiento especializado en relación con el Estado. 
Las comunidades de los ríos del Pacífico mantienen una significación cultural muy distinta sobre lo que es la naturaleza, la economía, la vida, el alimento y las relaciones sociales y de pareja. Y las personas que por causa de la migración forzada o no, acusan ese cambio en su entorno de manera desventajosa, en un nuevo medio en que les discriminan en razón de su diferencia.

Hay que hacer un desarrollo, para mejorar la calidad de vida de todas las comunidades, hay que reconstruir y fortalecer las economías, pero a través de un desarrollo alternativo, nadie quiere un desarrollo convencional, del estilo clásico, tipo revolución verde, plantaciones, queremos un desarrollo alternativo, ecológico, equitativo.

Comprender no es una opción frente a otras, sino la condición permanente de lo humano. La orientación en el mundo y el conocimiento del mundo implican siempre el momento de la comprensión. Y la comprensión se da en la interpretación de los mensajes transmitidos por el lenguaje. La interpretación comprensiva que somos, es por ello, la condición y el comienzo de todo conocimiento y de cualquier crítica (Ortiz-Oses, 2009).

Esa intención de comprensión de la naturaleza y del territorio llevó a las comunidades ancestrales a una sabiduría y modo de vida para la que la dinámica del capital hoy le reconoce valor, pero como comunidades y poblaciones locales -" guardianes" de la biodiversidad-.

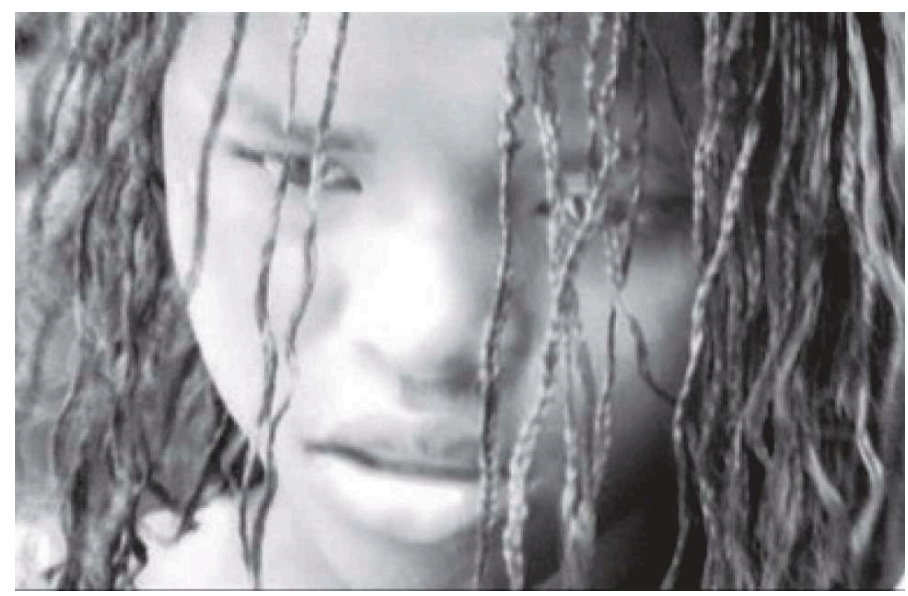

Fotograma del programa televisivo «Somos Pacífico» Cedido por la productora SELLO NEGRO, 2009 
Esta nueva significación y re-significación evidentemente como se ha mostrado, más que suscitar y posibilitar un cúmulo de transformaciones a favor de la vida y en la superación del ahondamiento histórico de las contradicciones sociales, ha servido en la legitimación de un orden cuyo interés se centra en hacer compatibles las organizaciones y estructuras económicas, sociales, políticas y culturales con las demandas del sistema económico mundial.

Así el medio ambiente y la biodiversidad se definen como objetos no solo de conocimiento sino también, de producción y de gobierno. Las alternativas al desarrollo y las economías de otros modos, requieren de ciertos desprendimientos en los que se hacen necesarios volver la mirada a la especificidad que manifiestan las visiones prácticas y discursos anclados en la diferencia epistémica, económica, política y cultural, donde podrían encontrarse verdaderas y valederas alternativas al desarrollo, no simplemente otra corrección al mismo "desarrollo” (Quijano, 2009).

También como respuesta a la compresión de su paisaje ancestral y su interacción con actores urbanos, se organiza en colectivos para gestionar valor a sus actividades y saberes, como es el caso de las parteras organizadas en la Asociación de Parteras Unidas del Pacífico - ASOPARUPA-, que han logrado valoración por el sistema de salud en Buenaventura y empoderan para que lo mismo se haga en otros lugares de población Afro.

Eventualmente el que se vea este hacer de la Mujer Afro como estrictamente reactivo, es porque en cualquier caso está conducido por una dinámica invasiva proveniente de las estructuras de poder económico y del estado, que la miran, han mirado y tratado como mero objeto de explotación.

Son ejemplos dicientes de cómo se materializan estos fenómenos del desarrollo en el caso de la Mujer Afro, ciertos eventos sucedidos con algunas comunidades Afro situadas en el Pacífico colombiano, como es el caso en las comunidades mineras a orillas de los ríos San Juan en el chocó y Telembí en Nariño, donde el contacto con la tecnología de dragas gigantes en los años 50 y 60, con exigencias de horario estricto de trabajo, recursos abundantes de vituallas y movilidad, conocimiento experto en máquinas y dispositivos mecánicos, desafió a las comunidades ancestrales a su contacto, integración e inter relación con un dispositivo modernizador localizado en mitad de sus ríos y de sus selvas y que impactaba de manera ubicua en todo el hacer comunitario. 
El segundo caso, más reciente es el de los cultivos de palma africana en las comunidades a orillas del río Mira en Tumaco y su área de influencia, donde la irrupción de una agricultura mecanizada con su dispositivo de tecnología mecánica, de estrictos horarios de trabajo y de nuevas técnicas agrícolas ha irrumpido en la selva y el paisaje comunitario, para cambiar, las nociones de sobrevivencia, del agua como recurso valioso, de la tierra como un bien que se ha de poseer y titular, distinto al conocimiento ancestral del uso y beneficio en la medida de la necesidad.

Uno de los efectos de este contacto con la modernidad por parte de las comunidades ancestrales del Pacífico colombiano, es la migración, incrementada de manera alarmante por la violencia llevada a sus suelos por las bandas armadas guiadas por los cultivos de coca.

Otro efecto es una apropiación de las nuevas tecnologías por parte de las comunidades para su desarrollo, así: el transporte de canoas por los ríos ha sido inevitablemente sustituido por el transito en canoas motorizadas que polucionan, pero que conectan con menor tiempo y esfuerzo las comunidades y las personas. La apropiación de motobombas y aún retroexcavadoras incrementan ingresos hasta niveles nunca alcanzados entre vecinos de las comunidades, tensionando aún más las relaciones intra comunitarias y la tensión entre unión/desgarramiento como valor de sobrevivencia.

También es un efecto, la adopción de una postura distinta con respecto al valor de la tierra, lo que se manifiesta en la búsqueda de mecanismos legales comunitarios para titular la tierra como defensa ante la agresión foránea —el estado y personas del interior del país-.

Para la Mujer Afro, su relación con las tecnologías mecánicas con que hasta ahora se debatían las comunidades, las afectaban y tocaban de manera indirecta, en el sentido de que ella no era sujeto contratado directamente por las empresas y su dispositivo de explotación; si bien era afectada por los cambios en costumbres horarios, cambios en el lugar y horas de comida, mayor carga en el cuidado de sus hijos y mayor dependencia económica por el abandono de formas productivas ancestrales en las que ella participaba en igualdad con el hombre.

\section{Para concluir}

La carga más pesada en situación de desplazamiento/destierro sufrido por las comunidades ancestrales Afro, lo sobrelleva la Mujer Afro, la cual 
cuando se moviliza, lo hace con sus hijos y casi siempre, en condiciones de no-retorno.

Para la Mujer Afro se trata y ha tratado siempre de la construcción de una familia dentro de un tipo de comunidad que se desarrolla por un cauce que se caracteriza por el tiempo, así como los intereses y estilo de vida compartidos, donde se habla con la propia voz y donde se habla y escucha de lo que se vive, se siente y afecta a cada una.

La tarea ahora es re-activar la vida, la Voz, donde se expresan sueños y anhelos de la mujer afro con toda la riqueza que guarda en su interior narrando lo que quiere Ser, sin paradigmas establecidos por el colonialismo sobre su carácter, potencial u oficio.

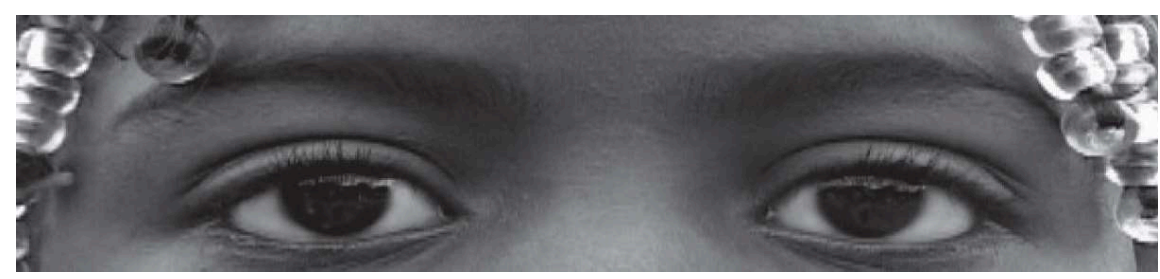

Fotomontaje a partir de una imagen cedida por el programa «Somos Pacífico» De la productora «Sello Negro», 2009

Este horizonte esperanzador pretende que cada día la Mujer Afro cuente su obra de vida transitada por des-esperanza, y paso a paso activada y colmada de Esperanza. Para dar y compartir un nuevo sentido a la vida que nos ha tocado vivir, a las nuevas experiencias, a los nuevos paisajes, a re-pensar y re-definir procesos y saberes ancestrales

\section{Referencias}

13 Salón Regional De Artistas Colombia. (s.f.). Biblioteca Departamental Valle del Cauca, Cali, Valle del Cauca, Colombia.

Arboleda, S. (2008). Conocimientos Ancestrales Amenazados y destierro Prorrogado: La Encrucijada de los Afrocolombianos. Cali: Lectura Seminario Universidad de San Buenaventura.

Bhabha, H. K. (1994). El lugar de la Cultura. Buenos Aires: Manantial.

Caicedo Salcedo, J. (2010). Mujer Afro: Voz de Esperanza y Re-existencia Universal. Cali: Tesis. Universidad San Buenaventura Cali. 
Escobar, A. (2005). Más Allá del Tercer Mundo: Globalización y Diferencia. Lectura Maestría. Universidad de San Buenaventura.

Griffin, F. J. (2004). When Malindy Sings: A Meditation on Black Women's Vocality. En R. G. O'Mally, B. H. Edwards, \& F. J. Griffin, Uptown Conversation: The New Jazz Studies (págs. 102-125). New York: Columbia UNiversity Press.

Lazzarato, M. (2006). Biopolítica: Agenciamientos y Estrategias de Creación. Sé Cauto , 14.

Ortiz-Oses, A. (2009). Hermeneutica y (post)Modernidad. En A. OrtizOses, \& L. Patxi, Claves de Hermeneutica. Bilbao: Publicaciones de la Universidad de Deusto.

Oto, A. d. (Fall de 2006). Apuntes sobre Historia y Cuerpos Coloniales. Recuperado el 28 de Marzo de 2009, de Wikipedia.

Quijano, O. (2008). El Adentro el Afuera y las topografías diferentes de la modernidad. UASB Quito: Tesis Doctorado Estudios Culturales Latinoamericanos.

Quijano, O. (2009). Posibles y Plurales Analíticas para no Perder el Acontecimiento. Popayán: Editorial Universidad del Cauca.

Toni Morrison. (s.f.). Recuperado el 22 de septiembre de 2009, de www. kirjasto.sci.fi/tmorris.htm

Walsh, C. (2007). Interculturalidad Critica/Pedagogia de-Colonial., Parte III: Pedagogías Críticas y De-coloniales. Bogotá. 